\title{
O EMPODERAMENTO DOS PACIENTES E A DELIBERAÇÃO MÉDICA
}

\author{
PATIENT EMPOWERMENT AND MEDICAL DELIBERATION
}

\section{Samuel Saliba Moreira Pinto ${ }^{1}$}

\section{Resumo:}

O presente artigo visa analisar, nas relações médicas, como seria possível garantir o empoderamento dos pacientes, ou seja, o seu protagonismo nos tratamentos, como condição de possibilidade para a justificação de uma deliberação médica bioéticamente limitada, atinente ao emprego de novas tecnologias. Dada a grande incerteza que paira sobre algumas das novas tecnologias, especialmente àquelas aplicadas no âmbito das ciências da saúde, imperiosa é a discussão jurídica acerca de limites para a deliberação técnica-médica, sem ignorar-se o desenvolvimento científico e a inovação, precisando o homem-cientista aceitar que deverá ter a dignidade humana como moldura intransponível para sua ação/inação, sob pena de a humanidade ver-se diante de danos eventualmente irreversíveis.

Palavras-chave: Bioética; Novas tecnologias; Medicina; Empoderamento.

\section{Abstract:}

This article aims to analyze, in medical relationships, how it would be possible to guarantee the consent of patients that is, its protagonism in the treatments, as a condition of possibility for the justification of a bioethically limited medical deliberation, regarding the use of new technologies. Due to the great uncertainty that hangs over some of the new technologies, especially those applied in the scope of health sciences, becomes necessary the legal discussion about limits for technical-medical deliberation, without ignoring scientific development and innovation, needing the man-scientist to

\footnotetext{
${ }^{1}$ Mestre em Direito pela Universidade do Vale do Rio dos Sinos - UNISINOS (São Leopoldo/RS); especialista em Direito Empresarial pela Pontifícia Universidade Católica do Rio Grande do Sul - PUCRS (Porto Alegre/RS); graduado em Direito pela Universidade da Região da Campanha - URCAMP (Bagé/RS); e advogado (OAB/RS n ${ }^{\circ 4.612) . ~ E-~}$ mail: samuel@ferrariadvogados.com. ORCID https://orcid.org/0000-0001-6553-3965.
} 
accept that he must have human dignity as an insurmountable framework for his action/inaction, under penalty of humanity being faced with eventual irreversible damage.

Keywords: Bioethics; New technologies; Medicine; Empowerment.

\section{INTRODUÇÃO}

Este artigo visa analisar a relação entre médicos e pacientes, buscando avaliar como seria possível garantir o protagonismo desses enquanto mecanismo de justificação para uma limitação bioética do emprego das novas tecnologias por parte daqueles, como medida de harmonização entre o espectro científico desenvolvimentista e a dignidade humana.

Para atingir tal desiderato, adotar-se-á o método teórico, analítico e descritivo, a fim de revisar a literatura relacionada à bioética e os textos normativos pertinentes, fazendo-se, inicialmente, uma breve avaliação da deliberação, cuja limitação se pretende, para então examinar-se a relação entre médicos e pacientes e o seu empoderamento. Posteriormente, avaliar-se-á como seria possível, a partir desse protagonismo dos pacientes, justificar-se uma limitação bioética para a deliberação médica.

\section{DELIBERAÇÃO}

\subsection{Considerações preliminares}

Se somente podem ser objeto de limitação os atos contingenciais, necessário, para a identificação de limitações para a atuação humana - notadamente a técnica/médica -, verificar-se aquilo que está dentro do espectro de deliberação. Isso porque delibera-se sobre as coisas que dependem do sujeito (da razão e da ação), que podem ser realizadas. Teoricamente, não se delibera sobre a natureza, a necessidade (anánke - lei da natureza, necessidade física ou natural) e a fortuna (týkhe - acaso, 
boa ou má sorte, acidentes em geral). (ARISTÓTELES apud CHAUÍ, 1994, p. 314, 342343 e 361).

Em Aristóteles, na medida em que o desejo é a causa eficiente da ação, necessariamente precisa ser realizável (apud SCHIO, 2009, p. 80); e, dada essa natureza de elemento desencadeador da deliberação, da qual surgirá a decisão, o desejo, a despeito de ser imprescindível, não se presta para gerar a ação em si. (GAUTHIER apud SCHIO, 2009, p. 80). Para Chauí (1994, p. 314), pois, "Deliberamos sobre aquilo que podemos escolher e escolhemos aquilo que a deliberação nos mostrou ser preferível"; e, em Schio (2009, p. 79), o processo de ação pode ser resumido por meio da seguinte ordem: desejo, deliberação, percepção, escolha e ato.

A deliberação, assim, seria "a consideração das alternativas possíveis que uma certa situação oferece à escolha", tendo por finalidade combinar os meios mais eficazes para a ocorrência do desejo, e, conforme Berti (1998, p. 154), apenas se relaciona com os meios, ou seja, com as coisas que estão em relação aos fins, não com os fins per se - malgrado visar ações futuras, sobre elas não incide, pois delibera-se sobre os meios. Não se confunde a deliberação, pois, com os meios, dado que apenas os analisa, e, "na ação humana, é falível, mas também insuprimível"; sem ela não há ação, apenas "o movimento impulsionado pelo instinto ou pela paixão". (SCHIO, 2009, p. 80-81).

Nessa linha, a deliberação refere-se àquilo que é ignorado e contingente, se prestando para extrair as possibilidades a fim de que 0 ato pretendido se realize, havendo espaço para decidir-se dessa ou daquela maneira. Quando se fala em deliberação, pois, fala-se em espaço "para a escolha humana", de modo que para uma ação ou omissão há a dependência do próprio agente - é, desse modo, "nos meios" que há a análise das coisas que estão ao alcance do indivíduo, que avaliará a sua adequação para a finalidade pretendida. (SCHIO, 2009, p. 81).

A noção de que o desejo é realizável advém da percepção, importante fenômeno ocorrente após a deliberação, onde "os meios mais eficazes e corretos estão presentes para a obtenção do fim", ou seja, nela - a percepção - "foram acrescidos os melhores meios para" executar tal fim, e, nesse ponto, "se adiciona a certeza de que os meios são realizáveis, i. e., que eles são passíveis de se tornarem realidade", cabendo "à escolha optar, guiada pela prudência, pelo melhor meio". (SCHIO, 2009, p. 83). Em 
continuidade, advém a escolha, que é a "opção preferida dentre as várias alternativas", tratando-se, assim, de "uma atividade comparativa na busca do melhor possível" e que "depende de uma reflexão fornecida pela deliberação". O resultado será a ação moral (práxis), que "É o objeto comum do intelecto (inteligência deliberante) e do desejo (vontade desejante)", tratando-se de um "contingente indeterminado, como o acaso", mas que com ele não se confunde. (SCHIO, 2009, p. 83-84).

Por essa razão, a despeito do controle sobre a decisão per se, o mesmo não pode ser verificado - no mais das vezes - sobre os efeitos dessa escolha, e, no caso das novas tecnologias, havendo potenciais danos - eventualmente irreversíveis -, fundamental a ação limitadora do agente da deliberação - in casu os médicos. A partir da identificação daquilo que está dentro do espectro de deliberação humana, possível a identificação dos limites dessa contingência e dos elementos hábeis a propiciar um balizamento - para a ação humana -, notadamente quanto ao emprego de novas tecnologias.

\subsection{Graus de incerteza científica}

Como primeiro passo para o estabelecimento de uma deliberação bioética acerca da utilização - ou não - das novas tecnologias, imperiosa é a identificação de critérios para a avaliação do desconhecimento daí advindo - da aplicação dessas novas tecnologias em tratamentos clínicos -, que servirão como meio de justificação para o agente da deliberação.

Conforme Farber (2011, p. 903-905), divide-se a incerteza lato sensu em (1) risco, (2) incerteza stricto sensu, (3) ambiguidade e (4) ignorância.

A primeira dimensão da incerteza lato sensu, o risco, na lição de Stirling e Gee (2002, p. 254), pode ser definida a partir de uma condição onde é possível a definição de um conjunto abrangente de todos os resultados possíveis, bem como a resolução de um conjunto de probabilidades, por meio de uma matriz de resultados; e, havendo 
concretude acerca dos riscos, possível a sua "quantificação probabilística" (CARVALHO, 2014, p. 69). ${ }^{2}$

A segunda dimensão será a incerteza stricto sensu, caracterizada pela existência de "confiança na integridade e plenitude de um conjunto definido de efeitos", sem que haja base - "teórica ou empírica" - válida para a confiável atribuição de probabilidades para os respectivos resultados. (CARVALHO, 2014, p. 69). ${ }^{3}$ Tanto na primeira (risco) quanto na segunda (incerteza) dimensão, há "uma capacidade descritiva dos efeitos bem definida", porém na segunda não há um "diagnóstico digno de credibilidade e confiança para atribuição de probabilidades causais". (CARVALHO, 2014, p. 69).

A terceira dimensão, a ambiguidade, se relaciona com a situação em que há base de sustentação para a descrição de uma probabilidade de impacto, mas os efeitos - potencialmente negativos - são precariamente conhecidos ou mesmo indefinidos. (CARVALHO, 2014, p. 69). ${ }^{4}$ Nesses casos - de ambiguidades -, lecionam Stirling e Gee (2002, p. 524-525) que mesmo havendo probabilidades descritivas apontando para os potenciais inconvenientes, tais efeitos ainda não puderam ser cientificamente definidos.

Como último grau de incerteza, ou seja, como dimensão de maior desconhecimento científico, Carvalho (2014, p. 69-70) indica a ignorância, onde "não apenas não há base para [atribuição de] probabilidades (como é o caso da incerteza)", mas a definição dos efeitos também acaba sendo extremamente deficitária. Nesse caso, está-se frente a um fator de surpresa, pois é possível a ocorrência de efeitos "que tenham sido totalmente excluídos da consideração"; e, sendo "incógnitas desconhecidas", seguro afirmar-se não ser possível a respectiva exemplificação, salvo para as situações já desveladas, que não mais frequentam essa dimensão de incerteza. (CARVALHO, 2014, p. 69-70).

2 Como exemplos de riscos, Stirling, Renn e Zwanenberg (2006, p. 288) apontam as inundações rotineiras, a segurança de transportes e as doenças conhecidas.

${ }^{3}$ Como exemplos de incertezas em sentido estrito, Stirling, Renn e Zwanenberg (2006, p. 288) apontam os carcinogênicos, as inundações decorrentes de mudanças climáticas e os valores mobiliários.

${ }^{4}$ Como exemplos de ambiguidades, apontam Stirling, Renn e Zwanenberg (2006, p. 288) os conceitos organismo geneticamente modificados e seus danos, o cenário do efeito estuda e os impacto energéticos. 
No caso das novas tecnologias, dado que podem redundar em "danos futuros possíveis não quantificáveis", o instrumento mais adequado para o balizamento da deliberação será o "Princípio da Precaução", configurando-se uma "receita para os desastres" a adoção de um sistema de gerenciamento de riscos que não leve em consideração a incerteza e a expectativa desses danos. (CARVALHO, 2014, p. 71 e 77).

O cabimento da precaução para o gerenciamento dos riscos decorre dos "elementos nucleares do princípio", quais sejam, "a existência de incerteza e a possibilidade de danos graves ou irreversíveis"; sendo importante consignar-se que a adoção de tal princípio, como base para a deliberação, notadamente sobre novas tecnologias, perpassa por situações em que a inação também possa gerar consequências irreversíveis e danos irreparáveis. No mais das vezes, a precaução terá aplicabilidade quanto aos riscos permeados por incerteza, ambiguidades e ignorância, cujas consequências possam ser graves ou mesmo irreversíveis, sendo que "A relevância da existência e da análise lançada sobre tais elementos para a aplicação e intensidade do princípio da precaução é evidente", vinculando-se a ideia de gravidade e irreversibilidade. (CARVALHO, 2014, p. 78-79). E a forma de utilização do referido Princípio, se mais ou menos incisiva, deverá ser balizada a partir da avaliação dos cenários - o pior e o melhor -, sendo imperioso que o agente da deliberação seja forçado a utilizar da sua imaginação (CARVALHO, 2014, p. 81). A aplicação do referido Princípio deve ter seu foco em evitar o pior cenário, e, ao mesmo tempo, evitar a perda dos possíveis benefícios advindos do melhor cenário ${ }^{5}$. (FARBER, 2011, p. 30).

Estabelecidas as dimensões da incerteza científica, e levando-se em consideração o Princípio da Precaução como elemento de integração para a justificação de eventual limitação para a deliberação, possível consignar-se que havendo grande incerteza sobre os potenciais danos - eventualmente irreversíveis - do

\footnotetext{
${ }_{5}$ Ao dizer respeito aos "riscos identificados, mas cuja probabilidade não é conhecida, apenas a magnitude extrema", a avaliação do pior cenário se relacionará mais com a dimensão das incertezas stricto senso; e, quanto ao Princípio da Precaução, se relacionará com as dimensões da ambiguidade e da ignorância, pois diz "respeito mais àqueles casos ou hipóteses alocadas fora do cálculo decisional", que sequer eram imagináveis ou, por terem sido tidos como inofensivos, foram erroneamente descartados. (CARVALHO, 2014, p. 83; FARBER, 2013, p. 17).
} 
emprego de determinada nova tecnologia, necessária grande atenção por parte daquele que possui o poder de decisão. In casu, o médico.

\subsection{Deliberação técnica e deliberação moral}

A tentativa de proposta de harmonização bioética entre as ciências da saúde e a dignidade humana (dos pacientes), baseada em uma inexorável limitação da deliberação técnica - médica -, por meio do empoderamento dos pacientes, perpassa pelo estabelecimento de uma diferenciação entre às ciências, notadamente frente à sua função de "produzir capital e entender os impactos causados pelas externalidades correlatas à [essa] produção". (ENGELMANN, 2014, p. 346).

Schnaiber (apud GOULD, 2012, p. 03) diferencia as ciências entre aquelas que são de produção e as que são de impacto: as primeiras levam a um aumento na produção, distribuição e consumo de bens e serviços, visando a geração de resultados - traduzidos por novos bens, sistemas, processos de produção ou materiais -; e as segundas, diferentemente, visam um aprimoramento da compreensão do homem acerca dos impactos ambientais e na saúde humana, decorrentes dos processos de produção, produtos e externalidades, ou seja, visam observar as mudanças no meio ambiente natural e na saúde humana.

Não se ignorando os aspectos bioéticos que são/deveriam ser inerente em tais ciências, notadamente a medicina, temos que podem ser incluídas preponderantemente - dentro dessa categoria, qual seja, de produção, notadamente porque a ciência moderna, como ensina Engelmann (2014, p. 346), além de observar e descrever a natureza, pretende uma interação. A presente pesquisa dirige-se àqueles que atuam na área das ciências de produção, especificamente os médicos, na medida em que podem deliberar sobre a vida humana e eventualmente geram desdobramentos éticos complexos - e que precisam ser repensados.

Frente à ausência de respostas por parte das ciências de produção (ENGELMANN, 2014, p. 346), precisará a humanidade, para uma adequada utilização das novas tecnologias, saber se conduzir a partir de standards bioéticos, que deverão "tratar dos problemas atuais e futuros de ordem ambiental e éticos que, 
fundamentalmente, dizem respeito às liberdades individuais", sendo essa uma discussão que diz respeito ao conjunto da sociedade impactado por benefícios e malefícios, transcendendo o plano eminentemente técnico-científico. (PINTO, 2014, p. 212).

Tendo como objeto de saber as novas tecnologias, a bioética "diz respeito a todos os setores da atividade humana: o início e o fim da vida, a engenharia genética, a biotecnologia moderna, a medicina e os medicamentos", entre outras, vindo justamente a colocar em dúvida os avanços tecnológicos (PINTO, 2017, p. 68-69), gerando/propondo limitações aos que decidem sobre a marcha desse desenvolvimento, tendentes ao cuidado com a própria vida - que assegura a presença humana no mundo. (KESKE, 2017, p. 26). Isso porque os avanços científicos, geralmente, apresentam tendências contraditórias: ao mesmo tempo em que "emergem como melhorias das condições materiais da existência humana", "aparecem como ameaças, colocando em perigo a vida humana", notadamente porque avançam "em searas ainda não totalmente conhecidas" (PINTO, 2014, p. 213). E essa "tensa relação" entre "antigas questões ainda insolúveis e que dizem respeito às condições mais íntimas do existir humano" e "os últimos desenvolvimentos tecnológicos que a sociedade atual logrou atingir" é que caracteriza os postulados e a própria razão de ser da bioética. (KESKE, 2017, p. 37).

Especificamente quanto às novas tecnologias médicas, há sempre grandes discussões de ordem moral. Desde a década de 1950, e. g., com o uso de equipamentos relacionados à hemodiálise e respiradores artificiais, e o próprio transplante de órgãos, que sendo uma grande inovação no uso de tecnologias nos tratamentos clínicos, acabou impactando drasticamente na própria caracterização da morte: o critério cardiotorácico (aspecto biológico) passou a "conviver" com o critério encefálico, que "mesmo também se baseando em elementos biológicos, relaciona-se ao viver, aos aspectos biográficos, à vida relacional da pessoa". (GOLDIM, 2018, p. 13-

\footnotetext{
${ }^{6}$ Conforme Goldim (2018, p. 35-36), quando baseado no critério cardiotorácico, o óbito pode ser constatado por qualquer pessoa no pleno uso e gozo de suas faculdades mentais, uma vez que é "autoevidente". De outro lado, quando baseado no critério encefálico, "o final do viver" é que determinará "o final da vida", sendo necessários conhecimentos específicos para esse diagnóstico.
} 
14, 33-35). Mesma coisa quanto à reprodução assistida, realizada desde a década de 1970 e que possui desdobramentos graves do ponto de vista ético, notadamente quanto aos embriões congelados, sua destinação e status. (GOLDIM, 2018, p. 41-42).

Recentemente, um cientista chinês afirmou ter modificado dois bebes humanos geneticamente, a fim de que não contraíssem HIV, o que gerou grande polêmica frente à proibição de tal prática em vários países, conquanto "modificações no genoma de embriões humanos" podem causar problemas no indivíduo e em seus descendentes, notadamente em razão de mutações "colaterais" que podem ocorrer (ROBERTS, 2018), sendo claro que a grande problemática envolvendo a edição genética humana advém do desconhecimento dos efeitos que tal prática poderia gerar a longo prazo. ${ }^{7}$

Goldim traz outros dois exemplos de casos em que a ciência médica poderia trazer graves dilemas éticos para a humanidade: primeiro com a notícia de produção em laboratório, "a partir de células de pele humana", de um cérebro humano ainda em estágio embrionário (GEWIN apud GOLDIM, 2018, p. 55); e, segundo, com a notícia da possibilidade de realização de um transplante de cabeça - acoplamento do corpo de uma pessoa morta em uma cabeça viva. (KNAPTON apud GOLDIM, 2018, p. 56). Referidos experimentos avançam em uma linha importante da nossa moralidade, dado que o cérebro é considerado a base da identidade humana, tanto de forma individual quando de forma coletiva; e, por isso, "esse procedimento é diferente daqueles já realizados com outros órgãos, como rins ou fígados, nos quais os pacientes receptores estão vivos". (GOLDIM, 2018, p. 56). Assim, "O risco de banalizar o uso de cérebro humanos criados em laboratórios ou de substituir corpos doentes por outros sadios, mantendo-se um cérebro", seria "destituir o ser humano de sua identidade" e "de sua dignidade”. (GOLDIM, 2018, p. 58).

Nos seus primeiros anos, a bioética "deu maior atenção às questões envolvendo a saúde e o exercício da medicina, especialmente as resultantes da incorporação das novas tecnologias, e aquelas envolvendo animais" (GOLDIM, 2018, p. 17), e, conforme Fonseca (2009, p. 152), "somente nos anos 1960", "período [...] fortemente marcado por importantes transformações culturais e sociais", tais como àquelas relacionadas com os

\footnotetext{
${ }^{7}$ Tal cientista foi condenado a penas de prisão e multa por tais atos. (G1, 2019).
} 
direitos humanos, a crise cubana e a guerra do Vietnã, bem como com a "introdução dos métodos contraceptivos" e as discussões sobre a legalização do abortamento, que começou a constituir-se - "seriamente" - como um campo de estudos. Aponta Goldim (2018, p. 17), todavia, que "a partir dos anos 1990, houve uma ampliação da discussão", para incluir "temas ambientais e as múltiplas vulnerabilidades - físicas, morais, sociais, econômicas ou políticas" da humanidade -, e, conforme Fonseca (2009, p. 152), "o maior impulso à bioética foi dado, sem a menor dúvida, pelo enorme avanço das tecnologias médicas, que levantou questões jamais colocadas".

Surgido a partir de um processo de revisão, próprio da experiência humana enquanto fenômeno temporal e histórico, esse "novo campo de conhecimento humano", a bioética, advém da "permanente descoberta de novos fatos/fenômenos, bem como novos campos de conhecimento", e preconiza uma reflexão acerca do que já se sabe ou se acha que sabe - e dos próprios métodos científicos. Assim, por meio de um permanente processo histórico, "operamos como que um virar-se sobre o próprio caminho andado, para verificarmos se os pressupostos que guiaram nossas análises ainda podem ser considerados consistentes". (KESKE, 2017, p. 30-31).

Funda-se a bioética, conforme Keske (2017, p. 33-35 e 36), em três princípios, que não se submetem a qualquer hierarquia, e devem ser integrados por parte do intérprete, quais sejam: o princípio da autonomia, que se relaciona com "o primeiro nível de cuidado" e envolve "as tradições de pertencimento", preconizando que os indivíduos possam deliberar, realizar escolhas pessoais e sejam respeitados por suas decisões acerca de questões relacionadas à sua vida e seu corpo; o princípio da beneficência, que é complementar ao princípio da não maleficência e preconiza "a obrigação ética de maximizar o benefício e minimizar o prejuízo", não prejudicando a vida alheia ou causando dor a outrem; e, por fim, o princípio da justiça, que preconiza o tratamento moralmente adequado e equânime a cada indivíduo. ${ }^{8}$

A discussão bioética, conforme Keske (2017, p. 35-36), pressupõe um equilíbrio por parte daquele que decide acerca do uso - ou não - de uma nova tecnologia, notadamente para que, de um lado, mantenha-se imparcial, "procurando evitar ao

${ }^{8}$ Consoante Fonseca (2009, p. 358), os princípios éticos básicos, em estrita observância aos Direitos Humanos, "seriam: a) respeito à autonomia, b) não maleficência, c) beneficência e d) eqüidade e justiça". 
máximo que aspectos sociais, culturais, religiosos, filosóficos, financeiros e de outros matizes interfiram nas práticas", e, de outro lado, seja assegurado o respeito ao pertencimento dos indivíduos, de forma que a decisão baseie-se no diálogo com os envolvidos e suas especificidades.

O confronto entre diferentes estruturas estabelecidas a partir de diferentes religiões e escolas filosóficas, bem como das ciências naturais, demonstra, justamente, a ausência de evidências de validade universal dos respectivos postulados, ou seja, a ausência de "respostas concludentes para os grandes enigmas da existência", de modo que demanda-se uma tentativa de identificação de "pontos de contato" entre uma estrutura e outra, a fim de que seja elaborado um "conjunto de procedimentos capazes de guiar o agir humano diante das mais avançadas tecnologias já disponíveis e que colocam essas questões fundamentais da vida em patamares de extrema complexidade". (KESKE, 2017, p. 38).

A identificação desses pontos de contato, a fim de que possamos "chegar a certo nível de validade de procedimentos capazes de guiar o agir humano" nas questões bioéticas, perpassa pela análise de todos os "sentidos instaurados por todas essas tradições do pensar, sejam de cunho religioso, filosófico e/ou científico", de modo que todos os pressupostos possam participar do diálogo bioético, sem que sejam - uma ou outra tradição - abandonadas e não reconhecidas como dignas. (KESKE, 2017, p. 3839). O conjunto de conceitos prévios de que a humanidade é portadora, desde o princípio da formação de cada indivíduo, sua educação e o pertencimento a uma tradição, a despeito de dirigirem as pessoas para determinada direção, não podem fixar a avaliação do juízo, como uma verdade absoluta, de forma a tornar-se um preconceito, "isto é, em juízos antecipados, sem, contudo, nos dedicarmos a analisar as outras formas de pensar e, principalmente, sem os esforço de procurarmos manter o foco no fato/fenômeno que se descortina diante de nós". (KESKE, 2017, p. 39-40). O autor contribui ao debate afirmando que:

Chega a soar como absurdo o fato de não nos permitirmos ouvir o que nos trazem todas essas tradições do conhecimento acerca da condição humana, quando a "coisa mesma" de que os temas da Bioética está a tratar se referem, do princípio ao fim, às próprias condições dessa vida 
humana, a ser considerada, por ela mesma, principalmente em função dos extremos em que devem ser pensados agora, no confronto com o desenvolvimento tecnológico atingido. (KESKE, 2017, p. 39, grifo nosso).

Ainda:

[...] aquilo que a Bioética lança diante de nós são os novos desafios à nossa compreensão da própria vida, de forma que se deve realmente procurar operar com tais questões no sentido da abertura às demais tradições, bem como não perder o foco da questão mesma colocada, ou seja, a própria vida humana. Caso contrário, estaremos ou impedindo ou obstruindo a possibilidade de se instaurarem novos sentidos no processo como um todo. (KESKE, 2017, p. 40).

Pensar a Bioética tendo-se por base o cuidado existencial em relação a vida do indivíduo, dos outros seres humanos e à própria biosfera, conforme Keske (2017, p. 40), torna premente o desafio de não "cairmos no puro casuísmo destituído de princípios", relacionado a um diálogo aberto, de forma a não fixar o debate "em idealizações a partir de princípios, sem focar um contexto mais amplo”, devendo haver um diálogo transdisciplinar intenso, "com todos os recursos e linguagens técnicas disponíveis", propondo-se soluções a partir dessa reflexão, "focada nos sujeitos que possam estar envolvidos em tais temas, estabelecendo-se [...] uma relação adequada entre todos os envolvidos, como sujeitos de conhecimento, com as situações fáticas vivenciadas". (KESKE, 2017, p. 40-41).

A partir do momento em que as novas tecnologias médicas possam redundar em riscos, dado o desconhecimento que paira sobre os desdobramentos potencialmente negativos do seu emprego, inobstante as melhorias que geram para a humanidade, imperiosa é a "reflexão bioética" no que toca ao(s) instrumento(s) jurídico(s) que possam atender ao desiderato de segurança/proteção, em celebração ao princípio da dignidade humana, de forma que a ética, a moral - aqui entendida como "um conjunto de valores próprios da pessoa humana, formulados racionalmente", conforme leciona Barretto (2016, p. 225) - e o direito, a partir desse quadro situacional, precisam formular novos limites e proteções jurídicas atinentes à regulação, produção e utilização dessas inovações. (PINTO, 2014, p. 214, 216 e 223). Assim, fundamental que a deliberação 
relacionada com as novas tecnologias, em especial àquelas aplicadas em tratamentos clínicos, possua uma limitação, em natural decorrência do desconhecimento acerca dos seus efeitos; sobretudo porque a sua utilização - ou não - é matéria que transcende as áreas técnicas, devendo a análise dos aspectos bioéticos dar-se na órbita do espaço público democrático. (PINTO, 2017, p. 69).

Diante dos desdobramentos bioéticos do uso das novas tecnologias, necessária, portanto, uma reflexão relacionada com a "adequação e validade dos princípios éticofilosóficos que a tradição estabeleceu"9, bem como com a respectiva "habilidade ou inabilidade para tratar de questões atuais e cada vez mais prementes da bioética e do biodireito". (PINTO, 2017, p. 72). Assim, se a evolução científica gerou uma ampliação no espectro da deliberação humana, restando exasperada a sua capacidade de intervenção na natureza (PINTO, 2014, p. 213-214), imperiosa uma harmonização entre as ciências - in casu da saúde - e a dignidade humana, tendo-se em conta uma limitação bioética para a deliberação, que não poderá ser apenas técnica.

A intervenção humana sobre coisas que antes pertenciam apenas ao acaso, tais como a fecundação, gestação, mutações genéticas etc, acabou gerando uma revolução estrutural na própria experiência moral do homem, sendo que essa mudança sinaliza uma crise dos valores da tradição ética-moral ocidental, que possui grande dificuldade no gerenciamento dos desdobramentos advindos da frenética evolução científica - que será objeto de reflexão da bioética, que precisará tentar formular respostas para os problemas morais, jurídicos e políticos advindos dessas novas tecnologias. (PINTO, 2014, p. 214).

A linha divisória "entre aquilo que nos é naturalmente dado e sobre o qual somos (ou éramos) completamente impotentes para interferir e aquilo que, não estando naturalmente [...] estabelecido, é objeto de deliberação entre fazer ou deixar de fazer" (PINTO, 2014, p. 214), acabou sendo mitigada pelas novas tecnologias, gerando, conforme Pinto (2014, p. 215), uma insegurança moral na sociedade, fazendo com que

\footnotetext{
${ }^{9}$ Conforme Pinto (2017, p. 69): O trânsito da bioética para o biodireito no âmbito das comunidades internacionais materializou-se no curso da segunda metade do século XX através de uma série de textos da ONU e da Unesco, os quais exprimem a necessidade de uma atenção crescente aos desenvolvimentos e possíveis avanços tecnocientíficos dentro do espírito da filosofia geral dos Direitos do Homem. (PINTO, 2017, p. 69).
} 
"as pessoas recorressem ao termo 'brincar de Deus', para designar o fato de os cientistas desvendarem e dominarem elementos da ciência que conferem poder sobre a natureza", ultrapassando o limite daquilo que é/era divino.

O movimento de avanço do conhecimento humano acerca de fenômenos sobre os quais não se possuía qualquer controle, propiciando que sobre eles - e a sua ocorrência ou inocorrência - se possa decidir, pressupõe um aumento do poder de decisão e de escolha, maximizando "o espaço da contingência do agir humano", e. g., por meio da possibilidade de escolha da cor dos olhos dos filhos, cabelo, pele etc, graças à engenharia genética, sendo evidentes as repercussões bioéticas dessas ações. (PINTO, 2014, p. 218-219). Nessa linha, Pinto (2014, p. 221-223) estabelece a necessidade de uma harmonização entre as deliberações técnica e moral, por meio da bioética, a fim de que os "problemas éticos" advindos do emprego das novas tecnologias sejam devidamente gerenciados, notadamente porque a deliberação moral possui indeterminações de ordem ontológica, ou seja, independe do conhecimento técnico - não sendo, logo, de ordem epistemológica.

Dito de outra forma, o agente possui um aumento no espectro de sua deliberação moral, na medida em que indeterminações dessa natureza não são minimizadas pelo progresso científico/acúmulo de conhecimento, ou seja, há uma ampliação do campo de aplicação do agir humano diante de situações que outrora não poderiam ser objeto de interação, cabendo agora ao agente moral - em alguns casos os pacientes em tratamento médico ou uma autoridade judicial ou administrativa deliberar sobre o caso, e, ao agente técnico (e. g. o médico), caberá a concretização da ação e a deliberação técnica, que é reduzida ${ }^{10}$ a partir do avanço tecnológico - pois indeterminações dessa natureza são de ordem epistemológica. (PINTO, 2014, p. 224225).

10 A redução do espectro de deliberação técnica pode ser ilustrada com os exames de sangue, que reduzem a gama de tratamentos possíveis de serem propostos pelo médico, pois a partir do momento em que o técnico sabe qual o tipo de sangue do paciente, obrigatoriamente terá que propor os tratamento específicos que a ciência, naquele momento, já identificou para pessoas daquele grupo sanguíneo. 


\section{EMPODERAMENTO DOS PACIENTES}

Conforme Wang (2018), "Confinar um indivíduo a uma cama ou um quarto, retirar-Ihe um órgão ou um membro, e aplicar nele substâncias que causam mal-estar e riscos à saúde", poderiam ser considerados crimes, entretanto, quando se constituem em procedimentos médicos, tornam-se lícitos, a despeito de nem sempre serem legítimos. A legitimidade dos procedimentos decorrerá do regular registro do médico em seu órgão de classe, que reconhecerá a sua qualificação, bem como do respaldo que a técnica adotada precisa ter na literatura e na prática da medicina; ademais, "o paciente, se adulto e capaz", deve ter consentido para as interferências que sofrera na "sua integridade física, privacidade e liberdade". (WANG, 2018). Esse consentimento, baseado em informações relevantes e ausente de coerção ou pressão, é "uma manifestação do princípio do respeito à autonomia, que reconhece no paciente um agente moral com capacidade e direito de fazer escolhas que dizem respeito à sua própria vida e corpo", sendo que suas escolhas devem ser respeitadas, a despeito de eventual discordância de terceiros. (WANG, 2018).

O respeito ao paciente advém do seu empoderamento, o que pressupõe uma alteração do modelo de atendimento, com uma aproximação entre os lugares ocupados - por médicos e pacientes - naquilo que se denomina "mesa de negociações", pois, ao buscar "serviços" dessa natureza, a pessoa precisa ter um atendimento claro e objetivo quanto aos tratamentos possíveis, tanto no que se refere a evitar danos, quanto à cura, sendo que em tal situação - de empoderamento - há um maior protagonismo da pessoa tratada, "perdendo a passividade diante das decisões tomadas ao longo desse percurso". (PORCIÚNCULA, 2017, p. 06).

Baseado na "autonomia do paciente sobre o paternalismo médico", o empoderamento não pressupõe nem uma transferência de responsabilidades, pois o produto do conhecimento técnico é inerente à função exercida pelos profissionais da saúde, e nem "que o profissional deva aceitar de pronto a primeira coisa que the pede 0 paciente". O que há é uma atuação mais ativa por parte do destinatário dos tratamentos, dado que diretamente afetado pelos seus resultados, sendo que o papel do médico não deverá ser o de "dizer aos pacientes o que fazer", mas sim "o de ajudá- 
los a escolher, informando sobre as opções terapêuticas, as consequências de suas escolhas, e auxiliando-os a entender o que eles realmente desejam ou temem". (PORCIÚNCULA, 2017, p. 06; WANG, 2018; GAWANDE apudWANG, 2018).

A revisão das condutas médicas, tradicionalmente pouco preocupadas com a vontade deliberante do paciente, pressupõe um questionamento tendente a alterar a tradição das escolas de saúde, historicamente associadas à tomada de decisão médica solitária, para incluir os pacientes na tomada das decisões. (PORCIÚNCULA, 2017, p. 06; BARCELLOS apud PORCIÚNCULA, 2017, p. 06).

E quanto às decisões em fim de vida, a deliberação "envolve diversas questões culturais, entre as quais a cultura da negação da morte e luta pela vida que deve ser mantida a qualquer preço", o que acaba não valorizando a autonomia do paciente, preponderando a decisão técnica, baseada "no conceito de beneficência e" influenciada "pelos valores culturais e morais" do médico, ignorando que a pessoa tratada poderá ter outro desejo. (DADALTO; AFFONSECA, 2018, p. 18).

Poder-se-ia defender, em uma atitude paternalista ainda predominante, que se deveria restringir ao médico "a decisão de se limitar ou suspender procedimentos ou tratamentos que prolonguem a vida do doente em fase terminal de enfermidade grave e incurável", pois seria o profissional "quem conhece os efeitos benéficos e colaterais de cada intervenção, bem como a possível evolução da doença, sendo capaz de identificar as condutas de limitação de suporte de vida que melhor" que atenderiam ao interesse da pessoa tratada; todavia, isso contraria a ideia de protagonismo/empoderamento dos pacientes, pois os coloca em uma posição subalternizada. (LAGO; DEVICTOR; PIVA; BERGOUNIOUX apud DADALTO; AFFONSECA, 2018, p. 18).

Alguns pontos podem ser colocados como incentivadores desse protagonismo, conforme Choosing Wisely ${ }^{11}$, que, tendentes a uma limitação da deliberação médica, pressupõem uma racionalização da tecnologia adotada nos procedimentos clínicos, e, assim, à própria inovação. (PORCIÚNCULA, 2017, p. 06-07; BARCELLOS apud

\footnotetext{
${ }^{11}$ Em tradução livre, "Escolhendo Sabiamente", é uma entidade criada pelo Conselho Americano de Medicina Interna, em 1998, cuja pretensão é garantir um melhoramento no atendimento na área da saúde, "com o estabelecimento de condutas mais preocupadas com o bem-estar e o protagonismo" de pacientes. (PORCIÚNCULA, 2017, p. 06-07).
} 
PORCIÚNCULA, 2017, p. 06-07). Ainda que possível, pois, o uso de um novo procedimento, tal poderá não convir.

Em primeiro lugar, temos que o excesso de intervenções nos procedimentos médicos não é condição de melhoramento da vida dos pacientes, especialmente quando desnecessárias e/ou ineficazes (BARCELLOS apud PORCIÚNCULA, 2017, p. 07). Assim, a partir do momento em que deixam de ser adotados procedimentos inócuos - por vezes invasivos -, possível apontar-se um maior respeito com a dignidade da pessoa tratada.

Em segundo lugar, uma facilitação na linguagem adotada por ocasião das recomendações e explicações sobre os tratamentos possíveis, inclusive "lançando mão [o médico] de recursos, como vídeos e peças gráficas", é medida que propicia uma maior compreensão por parte da pessoa tratada (PORCIÚNCULA, 2017, p. 07), que terá maior controle sobre aquilo que entende conveniente de ser adotado - ou não. Como o diálogo entre médicos e pacientes, no mais das vezes, é assimétrico, pois há certa fragilidade por parte dos doentes, "A linguagem utilizada deve ser adequada, com um vocabulário acessível e compatível com a capacidade de entendimento" da pessoa atendida. (GOLDIM, 2018, p. 20).

Em terceiro lugar, temos que uma medicina que aproxime pacientes e médicos deve pressupor que "clínicas e hospitais também discutam condutas e gerem referências sobre o que se deve ou não evitar no cotidiano de assistência", de forma que tal como no primeiro caso, possa garantir o bem-estar dos assistidos, ao mesmo tempo em que garante "economia nas redes de saúde" e "redução de adversidade". (PORCIÚNCULA, 2017, p. 07).

A dificuldade dos pacientes de garantirem um locus mais ativo/participativo nos seus tratamentos pode ser identificada, e. g., no tratamento relacionado à neoplasia de mama, dada uma cultura de que a mamografia seria um "exame de rastreamento incontestável", e, havendo um resultado positivo, adotar-se-ia um "protocolo de atendimento sem, muitas vezes, detalhamento" às pessoas acometidas por essa patologia. (PORCIÚNCULA, 2017, p. 07).

A sugestão seria a proposição de uma parceria entre pacientes e médicos, como mecanismo de educação para uma melhoria dos cuidados, "com o objetivo de promover 
o autocuidado", propiciando uma participação mais ativa nessa aprendizagem

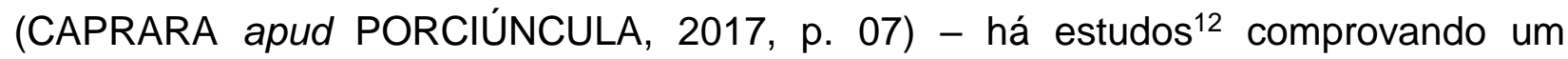
"aumento na qualidade de vida em 31\% dos pacientes que faziam o autorregistro de sintomas uma vez por semana e 7\% menos visitas às emergências para esse mesmo grupo ${ }^{13 "}$. (PORCIÚNCULA, 2017, p. 07).

Conforme Organização Pan-Americana da Saúde, dez perguntas podem garantir maior segurança para as pessoas em tratamento: "1. Qual o nome do problema que eu tenho? Qual o meu diagnóstico?”; "2. Quais as minhas opções de tratamento?”; “3. Quais são as minhas chances de cura?"; "4. Como é realizado o exame ou o procedimento?"; "5. Quando e como receberei os resultados do exame?"; "6. Como se soletra o nome do medicamento prescrito?"; "7. Quantas vezes ao dia e por quanto tempo devo usar esse medicamento?"; "8. É possível que haja alguma reação a esse medicamento?"; "9. Posso usar esse medicamento junto a outros, com algum alimento ou líquido?”; e “10. O tratamento mudará minha rotina?”. (apud PORCIÚNCULA, 2017, p. 07).

Da mesma forma, sugere-se cinco questionamentos para quem propõe o tratamento, conforme Choosing Wisely, quais sejam: (01) "Preciso realmente deste teste, tratamento ou procedimento?”; (02) "Quais os riscos?"; (03) "Existem opções mais simples e seguras?"; (04) "O que acontece se eu não fizer mais?"; e (05) "Quais são os custos?". (apud PORCIÚNCULA, 2017, p. 07).

O primeiro questionamento afigura-se pertinente, uma vez que a partir dos testes é possível que paciente e o médico determinem - ou tentem determinar - o problema, e, a partir daí as terapias que poderão ajudar no restabelecimento da saúde; o segundo questionamento se presta para que se saiba, de forma antecipada, "sobre os efeitos

12 Aponta a autora a Associação Americana de Oncologia Clínica (Asco) como a referência de tais estudos. (PORCIÚNCULA, 2017, p. 07).

13 Um exemplo trazido de mecanismo de empoderamentos dos pacientes de neoplasia na mama, inclusive com a utilização de tecnologia, é o desenvolvimento de um aplicativo, denominado Tummi, que permite o registro de dúvidas e a anotação dos sintomas, e, assim, propicia um autoconhecimento e uma postura mais participativa. (PORCIÚNCULA, 2017, p. 07). Diz uma das criadoras do aplicativo que dar ao paciente uma ferramenta de registro das suas atividades, propiciando organização da sua agenda e acompanhamento do tratamento, "coloca-o em uma postura mais participativa"; e, uma vez que "a forma de registro do aplicativo explica o que significa cada graduação do sintoma", há também o aprendizado acerca da identificação da "gravidade de cada situação", propiciando a adoção de medidas necessárias, "desde um simples analgésico até ir a emergência". (DALBOSCO apud PORCIÚNCULA, 2017, p. 07). 
colaterais e chances de obter resultados que não são os esperados", bem como sobre "se há possibilidade de o procedimento levar a testes e tratamentos adicionais". (PORCIÚNCULA, 2017, p. 07).

O terceiro questionamento se presta para que se possa optar por outros tratamentos cuja funcionalidade seja semelhante, e. g., se a mudança "de estilo de vida, como comer alimentos saudáveis ou exercitar-se mais" poderá ser uma alternativa segura e eficaz a outros tratamentos - invasivos ou nocivos. O quarto questionamento relaciona-se com a informação atinente a não adoção do proposto, notadamente quanto aos efeitos - eventualmente negativos; e o último questionamento relaciona-se aos custos financeiros - àqueles que correrão pela pessoa tratada e àqueles que correrão pela comunidade - e emocionais, além de tempo. (PORCIÚNCULA, 2017, p. 07).

Grootens-Wiegers e colaboradores apontam quatro capacidades que poderão aprimorar a tomada de decisões por parte dos pacientes: (01) a primeira implica em "aptidão de comunicar preferência", expressando uma escolha; (02) a segunda seria a compressão da terapia proposta, "o que pressupõe inteligência, domínio da linguagem, atenção direcionada para a informação e memória"; (03) a meditação acerca das consequências da adoção da medida proposta, sopesando os riscos e benefícios; e, por fim, (04) a "capacidade de apreciação", ou seja, "compreender as várias opções disponíveis" e "a relevância de tais alternativas para a própria condição clínica". (apud DADALTO; AFFONSECA, 2018, p. 17).

O empoderamento de pacientes, realizado por meio do respectivo protagonismo nos tratamentos médicos, gira em torno da escolha da medicação, orientações em doenças crônicas, e, inclusive, nos casos em que a medida mais adequada seja apenas a adoção de cuidados paliativos. (PORCIÚNCULA, 2017, p. 07).

Conforme Goldim (2018, p. 27), o empoderamento dá-se tanto para o que temporariamente acalma um mal, quanto para o que "adia uma crise sem resolver o problema - medida protelatória". A partir do momento em que a "saúde passou a ser vista não mais como a ausência de doença, mas sim com o estado de pleno bemestar", passou-se a direcionar a atenção não apenas para o quadro físico, mas também para o estado mental e social, justificando-se o cuidado paliativo, dirigido àqueles sem possibilidade cura. (GOLDIM, 2018, p. 30). E esses cuidados paliativos também 
"requerem habilidades humanísticas para cuidar de outras esferas de sofrimento [...], como medo, solidão, abandono, tristeza, falta de recursos socioeconômicos", além de habilidades de comunicação direcionadas ao paciente e sua família, para fins de definição dos objetivos a serem traçados; e, para o desenvolvimento de um trabalho integrado e direcionado ao alívio do sofrimento, necessárias características como empatia, compaixão, tempo e dedicação de uma equipe multiprofissional (experts em enfermagem, assistência social, psicologia, fisioterapia, terapia ocupacional, nutrição, capelania etc), já que os médicos são apenas um dos elementos desse sistema. (DADALTO; AFFONSECA, 2018, p. 17).

O "diálogo técnico", "com uma alta dose de empatia", no mesmo sentido, poderá gerar "consensos mais maduros e com menos probabilidade de erros", sendo que tal pressupõe justamente um maior tempo de interação entre profissionais e pacientes, 0 que propicia um empoderamento de conhecimento técnico por pacientes, tornando a tomada de decisões mais sóbria e assertiva em relação à condução dos tratamentos a aceitação, ou não, de determinado procedimento ("método diagnóstico ou terapêutico"); portanto, deverá levar-se "em consideração variáveis do prognóstico e o desconforto que esses métodos podem causar", além do "resultado real que impactará em sobrevida ou no controle de sintomas". (PAIM apud PORCIÚNCULA, 2017, p. 08). Também é necessário o empoderamento no caso de pacientes em situação de gravidade e/ou irreversibilidade, notadamente para "dar subsídios técnicos e reflexivos" para que ele e seu "núcleo familiar, [...] ao lado da equipe médica assistencial", possam "tomar as melhores decisões, pautadas nas melhores evidências científicas". (PORCIÚNCULA, 2017, p. 08; PAIM apud PORCIÚNCULA, 2017, p. 08). ${ }^{14}$

Importante, portanto, que a decisão, como reflexo do empoderamento dos pacientes, esteja no âmbito dos seus respectivos tratamentos, de forma integrada com

\footnotetext{
${ }^{14}$ Como ilustração, Dadalto e Affonseca (2018, p. 15) trazem o caso de pacientes pediátricos, onde a tomada de decisões nem é realizada por profissionais da medicina ou por pacientes, mas pelos seus pais, tutores ou curadores, cuja responsabilidade deveria ser vista não como um direito absoluto subjetivo -, mas como uma função inerente à sua qualidade, sendo que não seria possível para essas pessoas a assunção "a priori da tomada de decisões personalíssimas, que devem estar sempre" alinhadas com o melhor interesse do paciente-menor, pois "As questões de saúde inserem-se nos direitos de personalidade", não podendo ser transferidas para outrem, "nem mesmo para os pais ou responsáveis legais".
} 
e equipe médica, tendo-se por base o melhor interesse da pessoa enquanto destinatária das terapias, sendo inadequada, na ótica de Dadalto e Affonseca (2018, p. 16-18) a judicialização dessas questões, pois o eventual insucesso na resolução do conflito por meio do diálogo, deverá remeter a discussão, preferencialmente, para "a comissão de bioética da instituição, a comissão de ética, a diretoria clínica, o Conselho Regional de Medicina, o Conselho Federal de Medicina ou uma instituição de mediação privada".

A utilização das novas tecnologias nos tratamentos médicos, portanto, impacta justamente naquilo que Dadalto e Affonseca (2018, p. 16) denominam de "obstinação terapêutica", que persegue a manutenção da "vida" sem maiores questionamentos acerca do real benefício dessa artificialidade para o destinatário do tratamento - reflexo de uma "dificuldade social em lidar com a morte". Goldim (2018, p. 28) sinaliza que esse fenômeno deu-se com o início da Medicina científica, "que incorporou a farmacologia química e a tecnologia aos cuidados em saúde", o que fez com que houvesse uma perseguição pelo salvamento da vida, "a qualquer custo", entendendo a saúde como o oposto da doença e a morte como um "fracasso terapêutico". A aplicação médica dos avanços tecnológicos, conforme Dadalto e Affonseca (2018, p. 16), "modificou o curso natural de várias doenças, de forma positiva, como na substituição temporária de órgãos intensamente acometidos em pacientes com doenças agudas graves, mas também de forma negativa, como na manutenção artificial da vida biológica de pacientes" em situação irreversível, inclusive do ponto de vista da ilusão em "tratamentos experimentais".

A despeito dos avanços tecnocientíficos, previamente a adoção de determinada terapia, portanto, devem ser analisados os benefícios e malefícios, evitando-se a obstinação médica pela manutenção da vida, em prol da garantia de um processo de falecimento menos doloroso. (DADALTO; AFFONSECA, 2018, p. 17). Com efeito, imperiosa é a identificação de bases bioéticas limitadoras para a deliberação médica, sendo possível apontar-se o empoderamento de pacientes, traduzido em um protagonismo nos seus tratamentos clínicos, como um importante instrumento de integração para uma harmonização entre as ciências da saúde e a dignidade humana. 


\section{HARMONIZAÇÃO ENTRE MEDICINA E DIGNIDADE DOS PACIENTES}

A avaliação do empoderamento dos pacientes, como mecanismo de limitação bioética para o uso de novas tecnologias em tratamentos clínicos, pressupõe 0 confronto entre a deliberação médica-técnica e a deliberação moral (do paciente), sendo que o cerne desse debate será a identificação do protagonismo da pessoa com a saúde abalada como um elemento de contribuição para uma harmonização entre as ciências da saúde e a dignidade humana - elemento presente nas discussões éticas, jurídicas e políticas, e princípio fundamental de várias ordens constitucionais.

Quatro teses podem ser apontadas acerca da respectiva titularidade: a relacionada à universalidade, que diz que todos são titulares de dignidade $^{15}$; a relacionada à imperdibilidade, independendo da atuação ou consciência da pessoa ${ }^{16}$; a relacionada à exclusividade humana ${ }^{17}$; e, por fim, a da individualização, que pressupõe a dignidade humana a partir de uma visão atomizada do indivíduo (LOUREIRO, 2016, p. 164-165, 170-171), ou seja, para além de sua comunidade.

Sobre os avanços da biomedicina, Loureiro (2016, p. 173-174), aponta que tais podem ser tidos tanto como promotores de dignidade quanto como ameaças: primeiro por meio do acesso à saúde e como uma garantia estatal de prestações necessárias e essenciais à existência humana digna, e, em segundo, especificamente no campo da genética, com a criação de quiméricas e híbridos, além de outras misturas genéticas e intervenções na área da neurociência.

Dadalto e Affonseca (2018, p. 13), na mesma forma, apontam que a evolução da medicina, a partir da disponibilização de novas tecnologias, se de um lado aumenta a possibilidade de diagnósticos mais precisos e tratamentos mais eficientes, de outro lado "altera a história natural" das enfermidades e torna o prognóstico uma tarefa mais complexa. Poder-se-ia, assim, dizer que o "uso de equipamentos de suporte artificial de vida" permitiria a manutenção da vida, todavia, seria possível substituir

\footnotetext{
${ }^{15}$ Incluindo embriões in vitro.

${ }^{16} \mathrm{Em}$ um crime, p. ex., ou quando acometido por alguma enfermidade mental que prejudica sua consciência, o agente/sujeito não perde a qualidade de ser humano, com todos os Direitos e garantias de quem não cometeu um crime e encontra-se no pleno uso e gozo de suas faculdades mentais.

17 Não reconhece a "dignidade humana" para outros integrantes dos diversos ecossistemas.
} 
permanentemente uma função vital, tal como a respiratória? Seria adequado o uso desses equipamentos, ainda que a cura da doença per se não seja possível? (BEAUCHAMP apud DADALTO; AFFONSECA, 2018, p. 13).

A partir da cláusula geral de tutela da dignidade humana, "o direito à vida adquire nova leitura", ou seja, "a vida que se protege [...] não é a vida meramente biológica, mas sim digna", e considerando que no Brasil não há "qualquer tratamento" legislativo relacionado à dignidade para a morte, há "grande insegurança jurídica para todas as pessoas que lidam com a terminalidade - pacientes, família, equipe e instituição de saúde" -, situação que eventualmente gera malefícios a todos os envolvidos nessa indeterminação. (DADALTO; AFFONSECA, 2018, p. 19).

Conforme Ribeiro, o artigo 15 do Código Civil, que preconiza que "Ninguém pode ser constrangido a submeter-se, com risco de vida, a tratamento médico ou a intervenção cirúrgica" (BRASIL, 2002), deveria ser lido no sentido de que "ninguém, nem com risco de vida, será constrangido a tratamento ou a intervenção cirúrgica, em respeito à sua autonomia" (apud DADALTO; AFFONSECA, 2018, p. 19, grifei); mormente porque a dignidade deve perdurar até o fim da vida. E para se rejeitar o uso de ferramentas tecnológicas tendentes à manutenção da vida indigna, em oposição à morte, deverá a sociedade ampliar os "fóruns de discussão", possibilitando uma reflexão abrangente - sobre as questões envolvendo morte e dignidade humana. (DADALTO; AFFONSECA, 2018, p. 20).

Portanto, em situações relacionadas com doenças progressivas e incuráveis, onde a problemática do uso/não uso das tecnologias é mais aguda, os envolvidos (profissionais da medicina, pacientes e familiares) devem utilizar-se de uma abordagem humanista para as inter-relações estabelecidas, objetivando o consenso por meio "do aprimoramento das técnicas de comunicação e da capacidade de atuar com empatia e compaixão", de modo que a resolução de eventuais conflitos se dê de forma célere, evitando-se desgaste e sofrimento. (DADALTO e AFFONSECA, 2018, p. 120).

Como boas iniciativas nesse sentido, possível apontar-se alguns textos normativos do Conselho Federal de Medicina do Brasil (CFM), a despeito de certa inadequação, como a seguir será abordado. 
A Resolução № 1.995, de 2012, e.g., dispõe sobre as diretivas antecipadas de vontade dos pacientes em situação terminal, preconizando a importância "da autonomia do paciente no contexto da relação médico-paciente", reconhecendo "o direito do paciente de [...] definir previamente quais tratamento quer, ou não, receber no momento em que estiver incapacitado de expressar sua vontade" (WANG, 2018), prevalecendo "sobre qualquer outro parecer não médico, inclusive sobre os desejos dos familiares". Mesma coisa no caso de um representante designado para tal fim, cujas diretivas deverão ser consideradas pelo profissional da medicina. (CFM, 2012). Tal diploma pontua, especialmente, sobre a presença das novas tecnologias, que possam permitir "a adoção de medidas desproporcionais que" prolonguem "o sofrimento do paciente em estado terminal, sem trazer benefícios", ou seja, mantém artificialmente a vida, sem dignidade. (CFM, 2012).

Estabelece o texto normativo que a vontade do paciente precisa somente "ser levada em consideração", não dando um caráter cogente, portanto, e prevalecerá apenas sobre um parecer "não médico", ou seja, amplia as opções para médicos e pacientes, mas não respeita por completo a autonomia do paciente, pois não the dá o poder de recusar um tratamento; são os médicos que decidem quais vontades dos pacientes serão respeitadas - em uma atitude paternalista, conforme Wang (2018).

Essa postura não é nova, sendo importante a referência à Resolução № 1.805, de 2006, que permitiu a limitação/suspensão de procedimentos/tratamentos que prolongassem a vida de pacientes terminais, com "enfermidades graves e incuráveis", garantindo-lhes "os cuidados necessários para aliviar os sintomas que levam ao sofrimento, na perspectiva de uma assistência integral", respeitando a sua vontade ou de seu representante legal, tendo-se por base o princípio da dignidade humana, "como um dos fundamentos da República Federativa do Brasil", bem como o comando constitucional de que "ninguém será submetido [...] a tratamento desumano ou degradante". (Wang, 2018).

Inobstante, referida resolução determina que os pacientes continuarão recebendo "todos os cuidados necessários para" alívio dos "sintomas que levam ao sofrimento", bem como "assistência integral, [...] conforto físico, psíquico, social e espiritual", e, inclusive, "o direito da alta hospitalar". (CFM, 2006). Preconiza referido 
texto normativo, pois, a obrigação profissional de esclarecimento das "modalidades terapêuticas adequadas para cada situação", fundamentando e registrando em prontuário as decisões tomadas, assegurando-se que pacientes e/ou seus representantes tenham "o direito de solicitar uma segunda opinião". (CFM, 2006).

As diretivas antecipadas de vontade, contudo, poderão ser desprezadas se constatado, por meio da análise técnica, que estão em "desacordo com os preceitos ditados pelo Código de Ética Médica"; e, igualmente, "Não sendo conhecidas as diretivas antecipadas de vontade $[\ldots]$, nem havendo representante $[\ldots]$, familiares disponíveis" ou em caso de "falta de consenso [...]", deverão ser consultados os Comitês de Bioética aos quais tiver vinculação o profissional do caso, e, subsidiariamente, "à Comissão de Ética Médica do hospital ou ao Conselho Regional e Federal de Medicina", a fim de que as decisões sobre conflitos éticos possuam adequada fundamentação. (CRM, 2012).

A despeito da "importância e ampla aceitação do princípio da autonomia", Wang (2018) refere ser surpreendente que a legislação brasileira não seja clara quanto "ao direito dos pacientes de recursarem tratamentos", apontando certa contradição do "Código de Ética Médica do Conselho Federal de Medicina", que ao mesmo tempo em que pressupõe que o médico deva "'garantir ao paciente o exercício do direito de decidir livremente sobre sua pessoa ou seu bem-estar, bem como exercer sua autoridade para limitá-lo'”, "prevê uma exceção quando diz que é vedado ao médico 'deixar de obter consentimento do paciente ou de seu representante legal após esclarecê-lo sobre o procedimento a ser realizado, salvo em caso de risco iminente de morte'”. Há dúvida se tal exceção "se limita a casos em que não é possível consultar o paciente", e. g. "em situações de urgência em que o paciente esteja confuso ou inconsciente", o que seria defensável, "ou se inclui também situações em que o consentimento foi expressamente negado por paciente capaz. (WANG, 2018).

Permitir que o médico atue em contrariedade à expressa vontade do paciente capaz, ainda que em situação de risco iminente de morte, é negar-lhe "o direito de fazer escolhas fundamentalmente pessoais", acerca da sua tolerância para tratamentos e seus desdobramentos, a dialética entre qualidade e duração da sua vida, e, 
especialmente, "sobre como e onde preferem viver seus últimos momentos". (WANG, 2018).

Uma atuação legislativa no sentido de que assegurar "o direito do paciente adulto e capaz de ser tratado apenas quando der seu consentimento livre e informado", definindo "os requisitos para que uma pessoa seja considerada incapacitada para decidir sobre seu próprio tratamento médico", estabelecendo "princípios e procedimentos para decisões sobre o tratamento médico de um incapaz, incluindo neste grupo pacientes em estado vegetativo ou com consciência mínima", obrigando médicos e familiares a "acatarem as diretrizes antecipadas legalmente estabelecidas pelo paciente" e garantindo "o direito dos profissionais da saúde à objeção de consciência, mas com mecanismos para garantir que pacientes tenham suas escolhas respeitadas", conforme Wang (2018), afigura-se fundamental, notadamente para garantir autonomia aos pacientes, colocando na legalidade àqueles que prestem-Ihes auxílio para realizarem suas "escolhas", "perfeitamente éticas e humanas". O debate legislativo nesses termos poderia, conforme Wang (2018), oportunizar o início, no Brasil, de uma discussão sobre a eutanásia voluntária, "quando um médico deliberadamente retira a vida de um paciente para, a seu pedido, aliviar seu sofrimento", e suicídio assistido, tida como o "ato de um médico de auxiliar um paciente a retirar sua própria vida para aliviar seu sofrimento". (WANG, 2018).

As ciências da saúde inegavelmente promoveram - grandes - avanços científicos tendentes à exasperação da vida, entrementes, conforme Wang (2018), caberá ao Direito apontar as escolhas que os pacientes podem fazer quando se aproximam do seu ocaso, como medida de respeito à Dignidade Humana.

\section{CONSIDERAÇÕES FINAIS}

Há uma limitação natural no espectro de deliberação humana, notadamente quanto a determinados eventos naturais, o passado, a deliberação das outras pessoas etc, todavia, as novas tecnologias aumentam esse poder, propiciando mais liberdade para o homem. 
Nas ciências da saúde, as inovações invariavelmente aumentam a deliberação por meio de uma exasperação nas possibilidades de intervenção no corpo humano, gerando um deslocamento da fronteira entre o natural e o artificial, e, ao mesmo tempo, frente ao desconhecimento sobre os desdobramentos potencialmente danosos e eventualmente irreversíveis do uso dessas novas tecnologias, propiciam um incremento nos riscos daí decorrentes.

Como visto, não há um controle sobre os efeitos da escolha, mas apenas sobre a decisão per se, e, dadas as possíveis inconveniências de uma maior intervenção na saúde humana, fundamental a estruturação de balizas bioéticas para o agente da deliberação (médico, enfermeiro etc), como forma de harmonização entre as ciências da saúde e a dignidade humana, devendo tais limites bioéticos serem hábeis a garantir maior segurança da humanidade e meio ambiente. Devem os médicos, pois, propiciar/aceitar um protagonismo dos pacientes, possibilitando não apenas a deliberação técnica (médica), mas também - e principalmente - a deliberação moral (do paciente). E, a partir do protagonismo dos pacientes, com a garantia da prevalência da sua vontade, possível a identificação desse frame, posto que ainda que possível o uso de determinadas terapias para o seu tratamento, tais não poderão ser adotadas se assim não for o seu desejo.

Não se pretende, pois um bloqueio científico, o que poderia ocasionar outros prejuízos, mas sim uma responsabilidade, um cuidado por parte dos profissionais da saúde, que precisam entender que o desenvolvimento científico e a inovação devem alinhar-se com a dignidade humana, sendo fundamental o estabelecimento dessa moldura bioética para o homem cientista, que poderá dar-se a partir do empoderamento dos pacientes, como condição de legitimidade dos procedimentos médicos.

\section{REFERÊNCIAS}

BARRETTO, Vicente de Paulo. Uma nova (filosófica) leitura da ordem constitucional brasileira. In: STRECK, Lenio Luiz; ROCHA, Leonel Severo; ENGELMANN, Wilson. (Orgs.). Constituição, sistemas sociais e hermenêutica. Anuário do Programa de Pós Graduação em Direito da Unisinos. 1 ed. Porto Alegre/RS: Livraria do Advogado Editora; São Leopoldo: UNISINOS, 2016. 
BERTI. Enrico. As razões de Aristóteles. São Paulo: Edições Loyola, 1998.

BRASIL. Lei Federal n. 10.406, de 10 de janeiro de 2002. Institui o Código Civil. Disponível em: http://www.planalto.gov.br/ccivil_03/leis/2002//10406.htm. Acesso em: 26 jan. 2020.

CARVALHO, Délton Winter de. As dimensões da incerteza e as graduações de intensidade para aplicação dos princípios da prevenção e da precaução na decisão jurídica face aos riscos ambientais extremos. In: STRECK, Lenio Luiz; ROCHA, Leonel Severo; ENGELMANN, Wilson. (Orgs.). Constituição, sistemas sociais e hermenêutica. Anuário do Programa de Pós Graduação em Direito da Unisinos. 1 ed. Porto Alegre/RS: Livraria do Advogado Editora; São Leopoldo: UNISINOS, 2014.

CHAUI. Marilena. Introdução à história da filosofia. Dos pré-socráticos a Aristóteles. São Paulo: Editora Brasiliense, 1994. 1 v.

CIENTÍSTA chinês que criou bebês geneticamente modificados é condenado a três anos de prisão. G1, São Paulo, 30 dez 2019. Disponível em:

https://g1.globo.com/ciencia-e-saude/noticia/2019/12/30/cientista-chines-que-crioubebes-geneticamente-modificados-condenado-a-tres-anos-de-prisao.ghtml. Acesso em: 26 jan. 2020.

CONSELHO FEDERAL DE MEDICINA (CFM). Resolução no 1805/2006, 28 de novembro de 2006. Na fase terminal de enfermidades graves e incuráveis é permitido ao médico limitar ou suspender procedimentos e tratamentos que prolonguem a vida do doente, garantindo-Ihe os cuidados necessários para aliviar os sintomas que levam ao sofrimento, na perspectiva de uma assistência integral, respeitada a vontade do paciente ou de seu representante legal. Disponível em:

http://www.portalmedico.org.br/resolucoes/cfm/2006/1805_2006.htm. Acesso em: 26 jan. 2020.

. Resolução no 1995/2012, 31 de agosto de 2012. Dispõe sobre as diretivas antecipadas de vontade dos pacientes. Disponível em:

http://www.portalmedico.org.br/resolucoes/cfm/2012/1995_2012.pdf. Acesso em: 26 jan. 2020.

DADALTO, Luciana; AFFONSECA, Carolina de Aráujo. Considerações médicas, éticas e jurídicas sobre decisões de fim de vida em pacientes pediátricos. Revista Bioética. 2018; 26 (1): 12-21. Disponível em:

http://revistabioetica.cfm.org.br/index.php/revista_bioetica/article/view/1659. Acesso em: 26 jan. 2020.

ENGELMANN, Wilson. $O$ direito das nanotecnologias e a (necessária) reconstrução dos elementos estruturantes da categoria do "direito subjetivo". In: STRECK, Lenio Luiz; ROCHA, Leonel Severo; ENGELMANN, Wilson. (Orgs.). Constituição, 
sistemas sociais e hermenêutica. Anuário do Programa de Pós Graduação em Direito da Unisinos. 1 ed. Porto Alegre/RS: Livraria do Advogado Editora; São Leopoldo: UNISINOS, 2014.

FARBER, Daniel. 'Beyond Imagination': Government Blind Spots Regarding Catastrophic Risks. 2013. p. 01-19. Disponível em: http://dx.doi.org/10.2139/ssrn.2295767. Acesso em: 26 jan. 2020.

. Uncertainty. The GerogeTown Low Jornal. v. 99, 2011. p. 901-959. Disponível em: https://papers.ssrn.com/sol3/papers.cfm?abstract id=1555343. Acesso em: 26 jan. 2020.

GOLDIM, José Roberto. 10 ensaios de bioética. São Leopoldo: Ed. Unisinos, 2018.

GOULD, Kenneth. Unsustainable Science in the Treadmill of Production: The declining Salience of Impact Science in environmental conflict: Denver: American Sociological Association, Ago. 2012. Disponível: https://rampages.us/goldstein2014/wpcontent/uploads/sites/316/2014/08/Gould-Unsustainable-Science.pdf. Acesso em: 26 jan. 2020.

KESKE, Henrique Alexander Grazzi. Reflexão acerca da bioética pela perspectiva do cuidado existencial. In: ENGELMANN, Wilson; HUPFFER, Haide Maria. (Orgs.). BioNanoÉtica: perspectivas jurídicas. São Leopoldo: Trajetos Editorial, 2017.

LOUREIRO, João Carlos. Dignidad humana, (bio)medicina y revolución gnr (genética, nanotecnologia y robótica): entre la ciência y el derecho. IUS ET Scientia: Revista Eletrônica de Derecho y Ciencia, [S.1.], v. 2, n. 1, p. 187, 2016. Disponível em: http://hdl.handle.net/11441/58764. Acesso em: 26 jan. 2020.

PINTO, Gerson Neves. A invenção da bioética. Scientia luris, Londrina, v.18, n.2, p.211-226, dez.2014. DOI: 10.5433/2178-8189.2014v18n2p211. Disponível em: http://dx.doi.org/10.5433/2178-8189.2014v18n2p211. Acesso em: 26 jan. 2020.

. Os dois sistemas jurídicos contemporâneos - o common law e o da Europa continental - e um caso especial: a bioética. In: STRECK, Lenio Luiz; ROCHA, Leonel Severo; ENGELMANN, Wilson. (Orgs.). Constituição, sistemas sociais e hermenêutica. Anuário do Programa de Pós Graduação em Direito da Unisinos. 1 ed. Porto Alegre/RS: Livraria do Advogado Editora; São Leopoldo: UNISINOS, 2017.

PORCIÚNCULA, Bruna. Pacientes empoderados. Zero Hora, Porto Alegre, n. 1.348, 28 out. 2017. Caderno Vida, p. 06-08.

ROBERTS, Michelle. Por que o cientista chinês que diz ter editado genes de bebê causou revolta entre pesquisadores? BBC BRASIL, 26 nov. 2018. Edição de Saúde da BBC News. Disponível em: https://www.bbc.com/portuguese/geral-46325617. Acesso em: 26 jan. 2020. 
SCHIO. Sônia Maria. Aristóteles e a ação humana. In: NODARI, Paulo César; CESCON, Everaldo. (Orgs.). Conjectura: filosofia e educação. Vol. 14, n 01, Caxias do Sul/RS, 2009, p. 77-91. Disponível em:

http://www.ucs.br/etc/revistas/index.php/conjectura/article/view/5/5. Acesso: 26 jan. 2020.

STIRLING, Andy; GEE, David. Science, precaution, and practice. Public Healty Reports. v. 117, Association of Schools of Public Healty: Nov.-Dec., 2002. p. 521-533. Disponível em: https://www.jstor.org/stable/4598792?seq=1\#page scan tab contents. Acesso em: 26 jan. 2020.

STIRLING, Andy; RENN, Ortwin; ZWANENBERG, Patrick Van. A framework for the precautionary governance of food safety: Integrating science and participation in the social appraisal of risk. In: FISCHER, Elizabeth; JONES, Judith; SCHOMBERG, René Von. (Orgs.). Implementing the Precautionary: Principle Perspectives and Prospects. Cheltenham: Edward Elgar, 2006. p. 284-315. Disponível em: https://ideas.repec.org/h/elg/eechap/4075 14.html. Acesso em: 26 jan. 2020.

WANG, Daniel Wei Liang. O Direito e o fim da vida. JOTA, 30 dez. 2017. Disponível em: https://www.jota.info/opiniao-e-analise/artigos/fim-da-vida-direito-30122018. Acesso em: 26 jan. 2020. 